\title{
Influence of hydrofluoric acid treatment on electroless deposition of Au clusters
}

\author{
Rachela G. Milazzo ${ }^{* 1}$, Antonio M. Mio ${ }^{1}$, Giuseppe D’Arrigo ${ }^{1}$, Emanuele Smecca ${ }^{1}$, \\ Alessandra Alberti ${ }^{1}$, Gabriele Fisichella ${ }^{1}$, Filippo Giannazzo ${ }^{1}$, Corrado Spinella ${ }^{1}$ \\ and Emanuele Rimini ${ }^{1,2}$
}

\section{Full Research Paper}

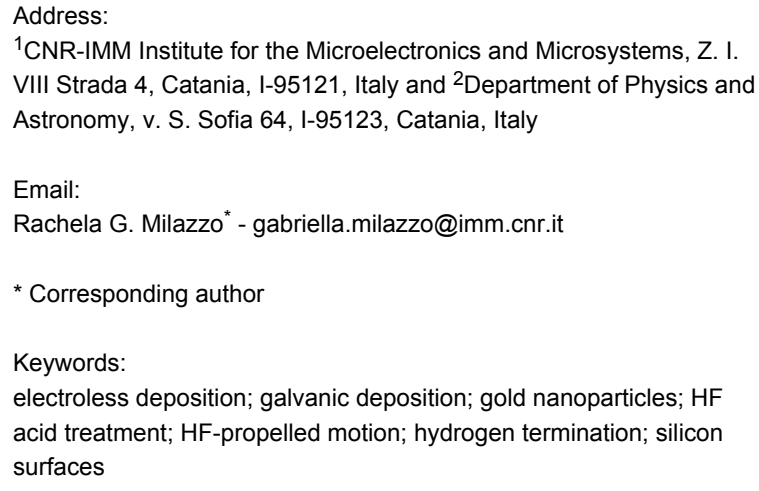

${ }^{1}$ CNR-IMM Institute for the Microelectronics and Microsystems, Z. I. VIII Strada 4, Catania, I-95121, Italy and ${ }^{2}$ Department of Physics and Astronomy, v. S. Sofia 64, I-95123, Catania, Italy

Email:

Rachela G. Milazzo* - gabriella.milazzo@imm.cnr.it

* Corresponding author

Keywords:

electroless deposition; galvanic deposition; gold nanoparticles; HF acid treatment; HF-propelled motion; hydrogen termination; silicon surfaces

\author{
Beilstein J. Nanotechnol. 2017, 8, 183-189. \\ doi:10.3762/bjnano.8.19 \\ Received: 07 August 2016 \\ Accepted: 28 December 2016 \\ Published: 18 January 2017 \\ This article is part of the Thematic Series "Self-assembly of \\ nanostructures and nanomaterials II". \\ Guest Editor: I. Berbezier \\ (c) 2017 Milazzo et al.; licensee Beilstein-Institut. \\ License and terms: see end of document.
}

\begin{abstract}
The morphology of gold nanoparticles (AuNPs) deposited on a (100) silicon wafer by simple immersion in a solution containing a metal salt and hydrofluoric acid (HF) is altered by HF treatment both before and after deposition. The gold clusters are characterized by the presence of flat regions and quasispherical particles consistent with the layer-by-layer or island growth modes, respectively. The cleaning procedure, including HF immersion prior to deposition, affects the predominantly occurring gold structures. Flat regions, which are of a few tens of nanometers long, are present after immersion for $10 \mathrm{~s}$. The three-dimensional (3D) clusters are formed after a cleaning procedure of $4 \mathrm{~min}$, which results in a large amount of spherical particles with a diameter of $\approx 15 \mathrm{~nm}$ and in a small percentage of residual square layers of a few nanometers in length. The samples were also treated with HF after the deposition and we found out a general thickening of flat regions, as revealed by TEM and AFM analysis. This result is in contrast to the coalescence observed in similar experiments performed with Ag. It is suggested that the HF dissolves the silicon oxide layer formed on top of the thin flat clusters and promotes the partial atomic rearrangement of the layered gold atoms, driven by a reduction of the surface energy. The X-ray diffraction investigation indicated changes in the crystalline orientation of the flat regions, which partially lose their initially heteroepitaxial relationship with the substrate. A postdeposition HF treatment for almost $70 \mathrm{~s}$ has nearly the same effect of long duration, high temperature annealing. The process presented herein could be beneficial to change the spectral response of nanoparticle arrays and to improve the conversion efficiency of hybrid photovoltaic devices.
\end{abstract}




\section{Introduction}

Gold nanoparticles on silicon substrates have shown quite interesting applications in the fields of Si nanowire (SiNW) catalysis [1-3], metal-assisted etching (MAE) [4] or even as electrical contacts in standard miniaturized devices [5]. Their ability to display enhanced surface plasmon resonance (SPR) at optical frequencies makes them excellent at scattering and absorbing visible light [6-8]. For these reasons, they have found an interesting application in the field of metal-semiconductor hybrid structures for solar energy conversion $[9,10]$. Among the different adopted methods to deposit Au nanoclusters on a substrate, electroless deposition based on galvanic displacement reactions is an efficient and versatile technique. It consists of manually dipping samples in a plating bath for few seconds without the need for application of an external current or potential [11-15]. Details about the reaction between $\mathrm{Au}^{+}$and $\mathrm{Si}$ atoms involved in the deposition are described elsewhere [16]. The morphology of gold by electroless deposition is quite complex and a number of basic questions remain to be clarified, such as the nature of the interface with silicon in the presence of hydrofluoric acid (HF). It has been reported in some studies that silicides are formed due to the strong interaction of $\mathrm{Au}$ atoms with $\mathrm{Si}$ [17]. On this topic, several contrasting reports are found in the literature but it is generally accepted that at a critical thickness (in the range of 2 to $5 \mathrm{ML}$ ) the gold seems inert and unable to mix with silicon. For gold deposited on silicon via galvanic displacement (GD), both Volmer-Weber and Stranski-Krastanov modes of growth have been suggested to be involved. It has been found that $\mathrm{Si}$ atoms diffuse outwards through the deposited gold layers during the growth process with the subsequent formation of Si oxide on their surface. The process stops after a certain thickness of oxide is formed and on top of it gold atoms agglomerate as solid clusters [18-21]. The optical properties of these gold clusters depend on their shape and morphology. It is reported in literature that the local field enhancement factor of gold nanoparticles depends on their geometry and it is higher for well-shaped spherical particles than for flat islands [22]. Generally, an additional postdeposition annealing step is usually required to improve the spectral response. In our previous study on the GD of $\mathrm{Au}^{+}$ions onto silicon substrates, we found that metal nanoparticles nucleate instantaneously and their subsequent growth is governed by diffusion in the solution [23]. In detail, we showed that by immersion of a $\mathrm{Si}(100)$ substrate for a few seconds in a solution containing $1 \mathrm{mM}$ $\mathrm{KAuCl}_{4}$ and 4.8 M HF, AuNPs with a mean radius of less than $10 \mathrm{~nm}$ and a density higher than $10^{10} \mathrm{~cm}^{-2}$ are formed. In the present work, we show that with proper HF treatments, the 3D Au clusters prevail over the flat regions obtained by layer-by-layer growth. Such a beneficial alteration requires only a manual immersion for a few seconds in a diluted hydrofluoric acid solution (DHF) with 6\% HF without the need for annealing or high power light irradiation [24].

\section{Results and Discussion}

The morphology of the samples was investigated with transmission electron microscopy (TEM). It has been reported in previous papers that the specimen preparation could alter the original and structural characteristics of the Au particles [25]. Therefore, we prepared the samples for TEM analysis using two different thinning procedures. One sample was obtained after a conventional TEM preparation technique, including mechanical and high energy ion thinning $\left(\mathrm{Ar}^{+}\right.$ions at $\left.5 \mathrm{keV}\right)$. The other one was prepared instead with the so-called "gentle milling" procedure using low energy $(0.1-1 \mathrm{keV}) \mathrm{Ar}^{+}$ions (see details in the Experimental section). The results are compared in Figure 1 that shows a plan view TEM of the silicon substrate after the same gold deposition process but prepared following the standard (Figure 1a) and the gentle milling (Figure 1b) procedures, respectively. The morphology is drastically modified by the high energy $\mathrm{Ar}^{+}$ion thinning, where the mean particle size is about $20 \%$ larger and the density increases by about $30 \%$ with respect to the low energy $\mathrm{Ar}^{+}$beam thinning procedure. The particles in Figure 1a are more spherical in shape with light grey areas of irregular shape, while in Figure 1b, the clusters are elongated and we observe square light gray regions. Clearly, gold atom rearrangement occurs in the sample during the standard thinning process that probably results from the heating of the sample due to the higher $\mathrm{Ar}^{+}$ion energy. In order to avoid artifacts, we therefore adopted the gentle milling procedure for all the samples to be analyzed by TEM. We tested the reliability of the mechanical thinning procedure by repeating both the HF pretreatments and the deposition step on a Si sample already thinned and then ready for TEM analysis. The Au cluster morphology was quite similar (see Supporting Information File 1, Figure S1) to that obtained by deposition on bulk substrates. As a result, we used standard wafers for deposition, and the samples were mechanically thinned and gently milled for TEM observations.

\section{HF treatment before Au deposition}

The Si(100) substrates were cleaned following the procedure described in the experimental section. Some of them were subsequently immersed in DHF (diluted HF, 6\% HF) for $10 \mathrm{~s}$ and some others for $240 \mathrm{~s}$. The electroless gold deposition takes place then by immersion in the plating solution for $3 \mathrm{~s}$. The TEM images of the corresponding samples are reported in Figure 2a,b, respectively. The gold morphology clearly varies with the time of the DHF pretreatment. After $10 \mathrm{~s}$ in DHF (see Figure 2a), Au atoms uniformly assemble on the Si substrate with elongated and wide structures of a few tens of nanometers 


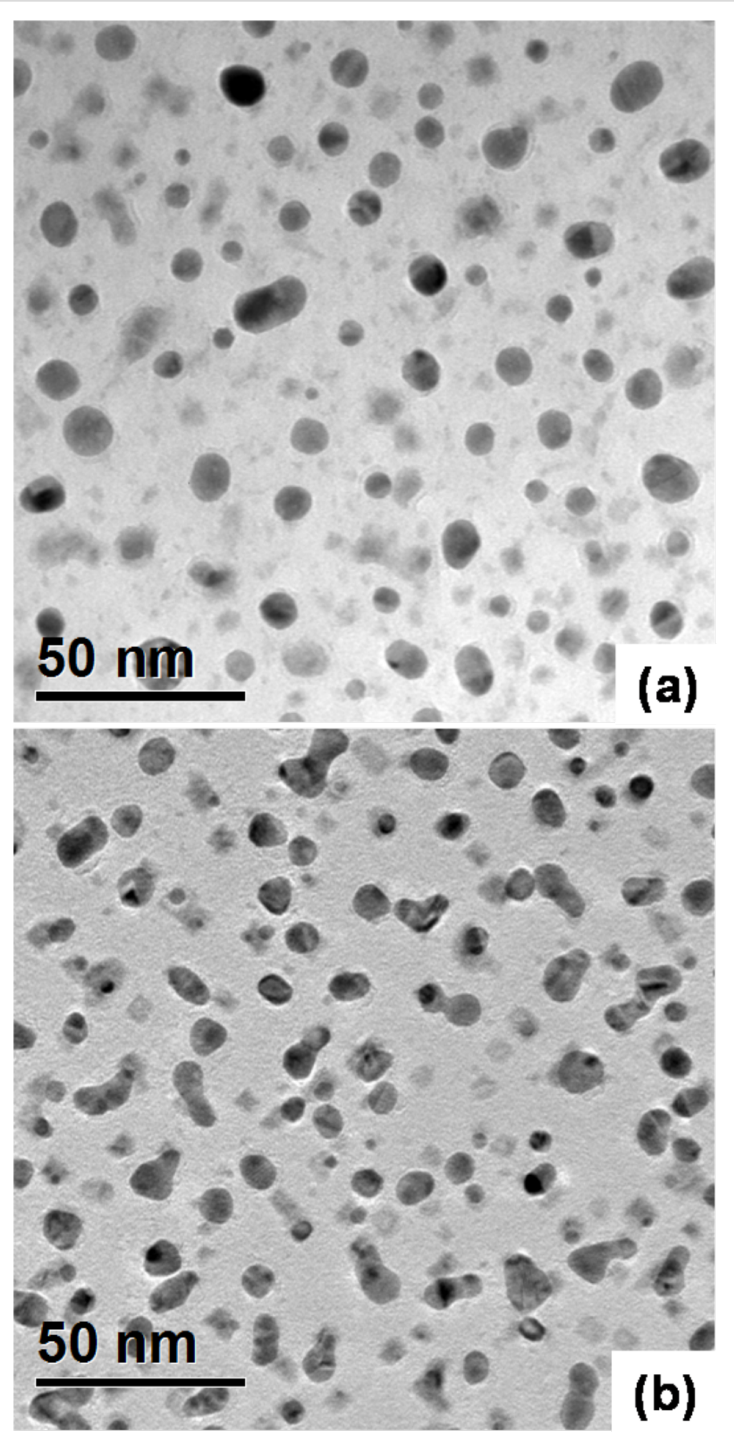

Figure 1: Plan view TEM micrographs of AuNPs electroless deposited on a Si substrate by immersion for $3 \mathrm{~s}$ in the solution after a DHF pretreatment of $240 \mathrm{~s}$; sample preparation (a) standard high energy and (b) gentle milling procedure. long. After $4 \mathrm{~min}$ in DHF (Figure 2b), they arrange as small particles of spherical shape with a radius of less than $10 \mathrm{~nm}$. Although the images were taken in bright field mode, a huge mass contrast between light gray, thin regions of square shape (labeled 1 in Figure 2b) and the dark, thick round particles (labeled 2 in Figure 2b) is clearly shown.

The two samples were also analyzed by Rutherford backscattering (RBS) measurements with $2 \mathrm{MeV} \mathrm{He}^{+}$ions in order to obtain the areal density of the deposited gold atoms, which was found to be $4.24 \times 10^{15}$ atoms $\mathrm{cm}^{-2}$ for sample (a) and to $4.73 \times 10^{15}$ atoms $\mathrm{cm}^{-2}$ for sample (b). By comparing these results with the fractional covered area measured by the TEM micrographs we estimated an equivalent mean thickness of $3 \mathrm{~nm}$ and $10 \mathrm{~nm}$, respectively. So, in other words, in the first case the layer-by-layer growth prevails while a $3 \mathrm{D}$ arrangement is promoted by the DHF pretreatment of $240 \mathrm{~s}$. It is well known that HF strongly modifies the silicon surface roughness [26-29] and wetting properties [30]. The surface-free energy of gold is $1410 \times 10^{-3} \mathrm{~J} / \mathrm{m}^{-2}$, while that of $\mathrm{Si}$ and $\mathrm{SiO}_{2}$ are $1240 \times 10^{-3} \mathrm{~J} / \mathrm{m}^{2}$ and $400 \times 10^{-3} \mathrm{~J} / \mathrm{m}^{2}$, respectively [31]. The native $\mathrm{SiO}_{2}$ is completely etched after $10 \mathrm{~s}$ (etch rate $500 \AA / \mathrm{min}$ ) so nucleation occurs on the hydrogenated silicon surface [32]. The roughness of the Si surface after a pretreatment of 4 min in DHF was measured by AFM, and the obtained root mean square (RMS) was $3 \mathrm{~nm}$, which is about one order of magnitude higher than a typical Si wafer (Figure 2c). Consequently, the surface-free energy increases [33] for a rougher surface and promotes $3 \mathrm{D}$ cluster formation by offering preferential sites for nucleation as apex or surface discontinuities.

\section{HF postdeposition treatment}

So far we have shown the influence of a DHF pretreatment on the subsequent $\mathrm{Au}$ deposition regarding the shape and morphology of the nanoclusters. We now consider what happens if the
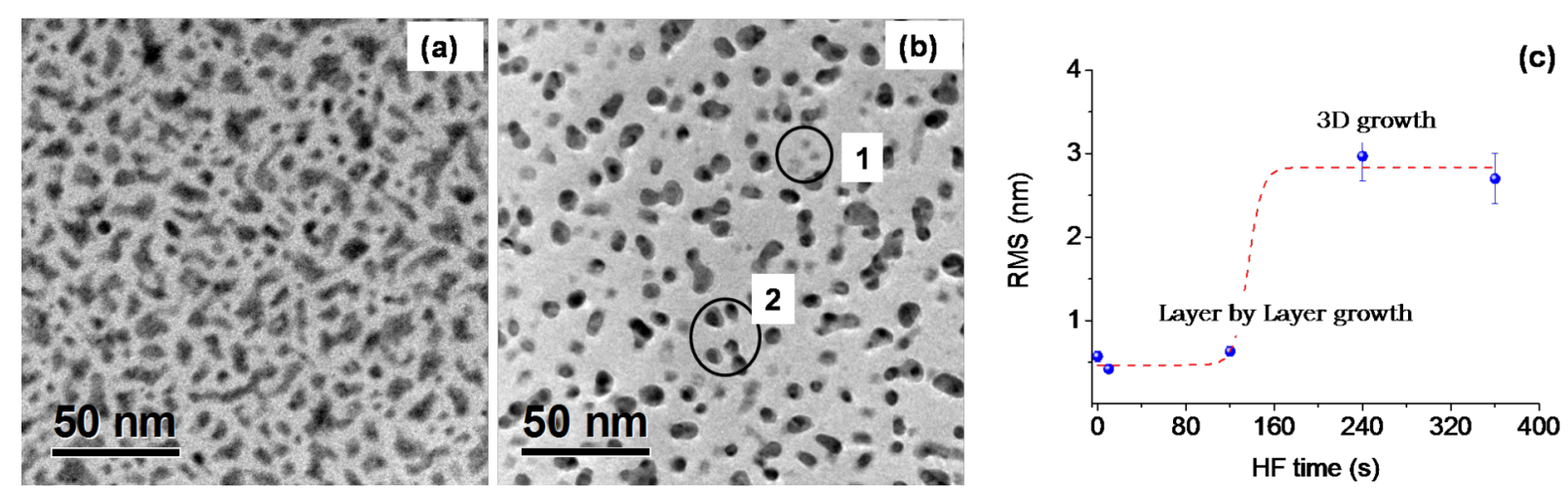

Figure 2: Gold electroless deposition on $\mathrm{Si}(100)$ after an DHF pretreatment of $10 \mathrm{~s}$ (a) and $240 \mathrm{~s}$ (b); root mean squared (RMS) for the corresponding Si substrates (c) measured with AFM. 
DHF treatment is performed after the gold deposition. There are many papers dealing with dynamic coalescence of metal nanoparticles in liquids [34-36]. In a previous work, we found that silver nanoparticles are subjected to Smoluchowski [37] ripening in DHF solutions by increasing their size and decreasing their surface density. For the case of gold nanoparticles on $\mathrm{Si}$, we expect a more complex scenario due to the stronger interaction between gold and silicon with the formation of quasiheteroepitaxial layers. Figure 3 reports the morphologies observed by AFM (in tapping mode with a silicon tip of 10-15 nm curvature radius) of Si samples with AuNPs before (Figure 3a) and after (Figure 3b) an HF postdeposition treatment of $70 \mathrm{~s}$.

The postdeposition treatment clearly results in a much flatter surface morphology than in the untreated sample. This effect can be quantified by calculating the root mean square (RMS) roughness from the two $1 \times 1 \mu \mathrm{m}$ scans in Figure 3, showing a decrease in the RMS value from $2.53 \mathrm{~nm}$ for the untreated sample to $1.16 \mathrm{~nm}$ after the HF treatment. This indicates a more uniform height distribution of clusters with respect to the substrate after the postdeposition treatment. To better illustrate this aspect, the histograms of the $z$ values (in terms of deviation from the mean height) extracted from the two AFM images are also reported in Figure 3c, showing a broad distribution in the as-deposited sample, with an asymmetric tail extending toward lower $z$ values, whereas a much narrower distribution is observed after the HF treatment.

The corresponding plan view TEM micrographs of the two samples are also reported in the inserts of Figure $3 \mathrm{a}$ and Figure 3b, respectively. The selected area electron diffraction (SAED), shown in Supporting Information File 1, Figure S2, of the AuNPs presents a bright spot in the (200)Au ring along the (400)Si directions indicating a heteroepitaxial arrangement of the deposited Au atoms, as also previously reported [21]. The intensity of this spot is reduced after HF treatment so one could envisage that the flat gray regions are heteroepitaxial with the substrate orientation. The $3 \mathrm{D}$ arrangement of the $\mathrm{Au}$ atoms after the HF solution treatment indicates that the heteroepitaxial relationship with the substrate is partially lost.

Moreover, the amount of $\mathrm{Au}$ on the sample, as measured using RBS, does not change even after an HF treatment of $70 \mathrm{~s}$, indicating that the atomic arrangement is not associated to dissolution of the deposited gold atoms (see Supporting Information File 1, Figure S3).

For a better understanding of the process taking place under immersion in HF we prepared a sample with large, flat regions, obtained after a short HF pretreatment followed by an immersion for $20 \mathrm{~s}$ in the plating solution. The morphology of gold
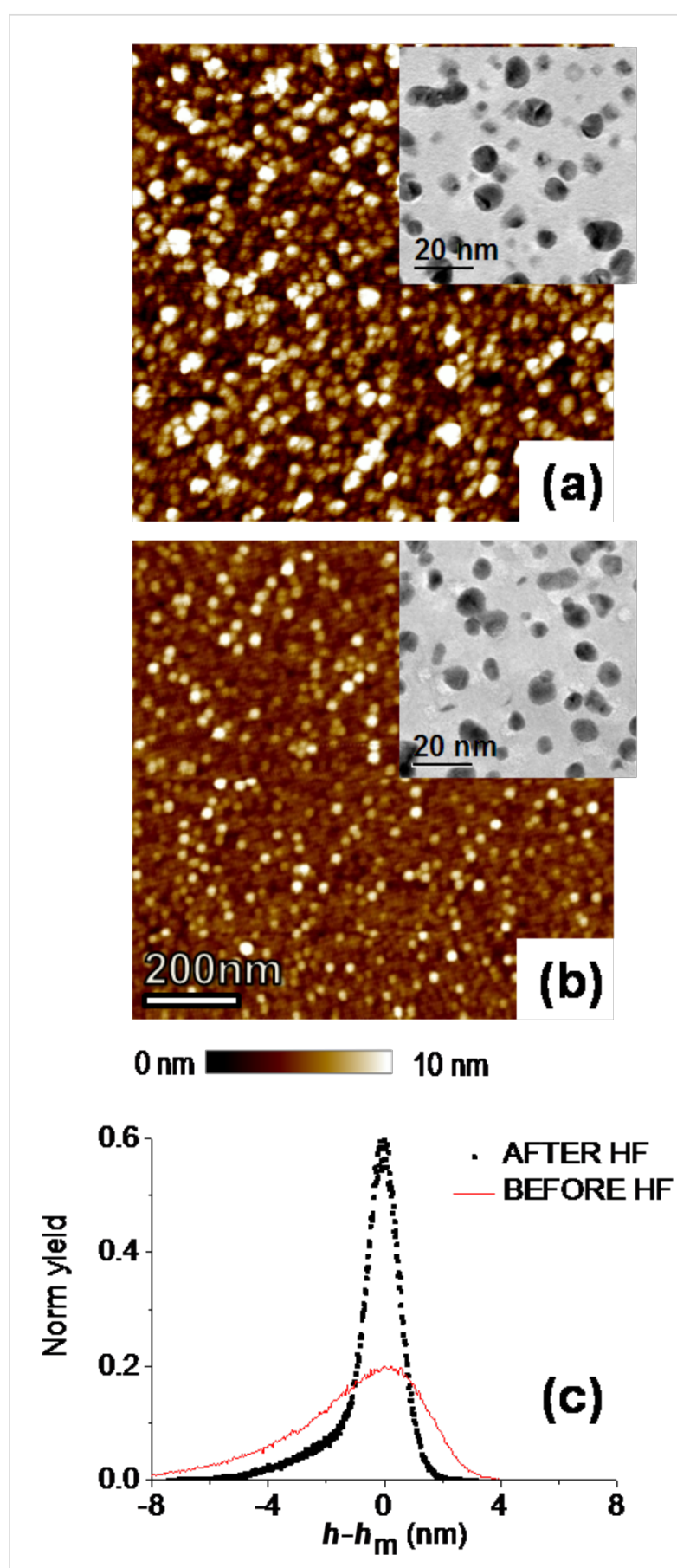

Figure 3: AFM z-scan of Si sample with AuNPs before (a) and after (b) a postdeposition bake in HF for $70 \mathrm{~s}$, with the corresponding TEM images in the upper right hand part. (c) Height distribution relative to the mean value, as calculated from AFM images.

was examined with plan view TEM and scanning transmission electron microscopy (STEM) in high-angle annular dark-field imaging (HAADF) Z-contrast (atomic number) imaging mode, while the crystalline structure was analyzed in detail with X-ray diffraction. Figure $4 \mathrm{a}$ and Figure $4 \mathrm{~b}$ are the plan view TEM of the samples before and after the HF postdeposition treatment 
for $70 \mathrm{~s}$. The more discernible effect is a pronounced change in the fractional covered area that varies by about $15 \%$. By using a STEM detector with a large inner radius (a HAADF detector) electrons are collected which are not Bragg scattered. As such HAADF images show little or no diffraction effects, and their intensity is approximately proportional to $Z^{2}$. The HF postdeposition treatment levels off the intensity distribution of the corresponding STEM micrograph, indicating a more uniform thickness for the gold particles as clearly seen by comparing Figure $4 \mathrm{c}$ and Figure 4d, respectively.

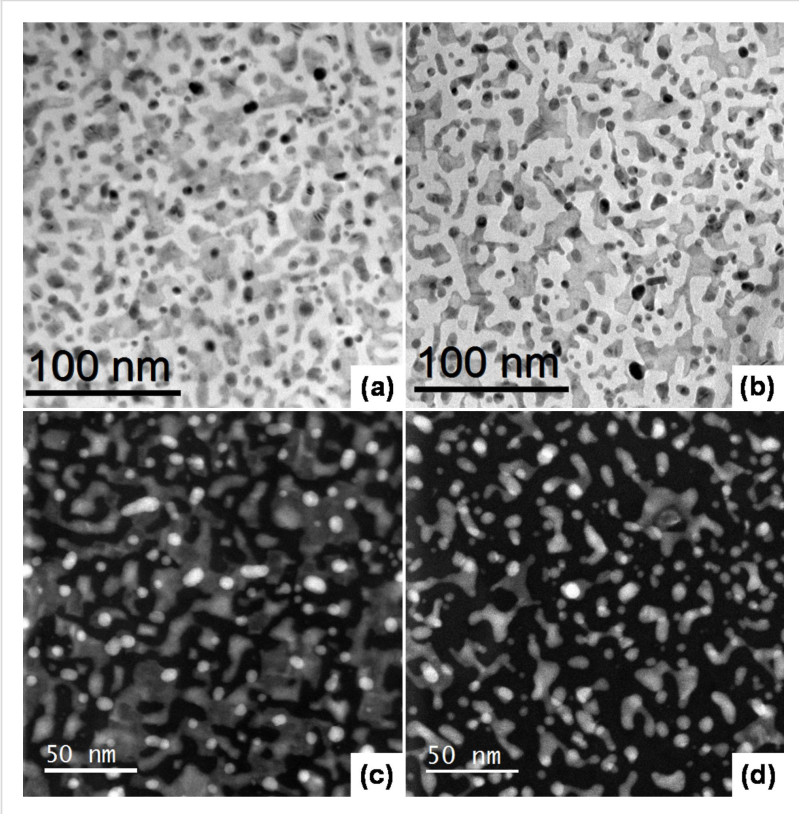

Figure 4: Plan view TEM of Si sample with Au islands obtained with $20 \mathrm{~s}$ immersion in the plating solution (a); the same sample after a HF postdeposition treatment of $70 \mathrm{~s}(\mathrm{~b})$ and (c) and (d) STEM image of (a) and (b), respectively.

The samples were also inspected with X-ray diffraction (Figure 5). Two different configurations were adopted. In the
Bragg-Brentano geometry we observed a significant (200) Au peak at $2 \theta=44.3^{\circ}$. Although the (111) peak at $38.2^{\circ}$ was expected to be the most dominant (the bars represented the computed intensities for a powder sample), the dominant peak at $2 \theta=44.3^{\circ}$ indicates the occurrence of texturing in the $\mathrm{Au}$ cluster orientation. The (111) Au peak at $2 \theta=38.2^{\circ}$, measured with grazing incidence X-ray diffraction, showed the presence of randomly oriented Au clusters coexisting with the heteroepitaxial regions on the Si substrate.

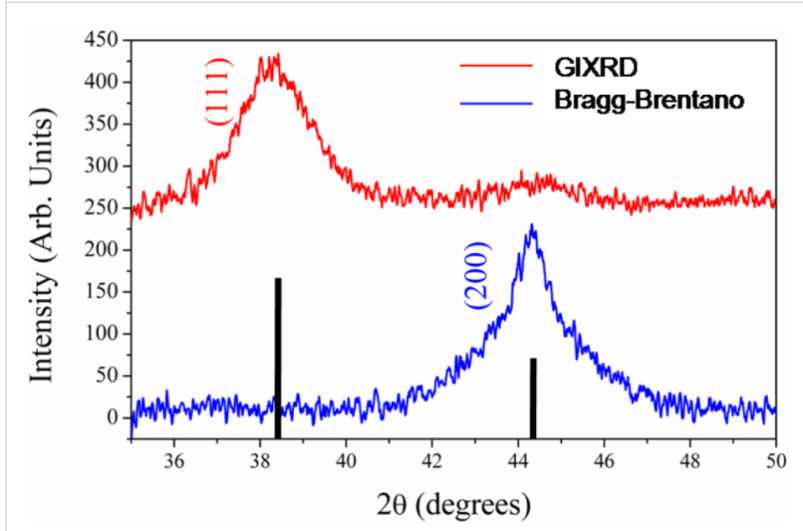

Figure 5: Diffraction profile of sample with AuNPs from a $20 \mathrm{~s}$ deposition for the grazing incidence (red, upper) and for the Bragg-Brentano (blue, lower). The bars represent the computed intensities for a random Au powder in the Bragg-Brentano geometry.

Moreover, the shape of the (200) diffraction peak indicates that two families of grains, both exhibiting texturing in the [001] crystallographic direction, are present. The deconvolution of the signal is reported in Figure $6 \mathrm{a}$ and the size of the corresponding crystals is determined by the Scherrer formula [38].

We observe a broad peak, with a FWHM of $2.6^{\circ}$, associated with large regions about $3 \mathrm{~nm}$ thick. They coexist with small 3D clusters that are about $15 \mathrm{~nm}$ high and whose contribution to the
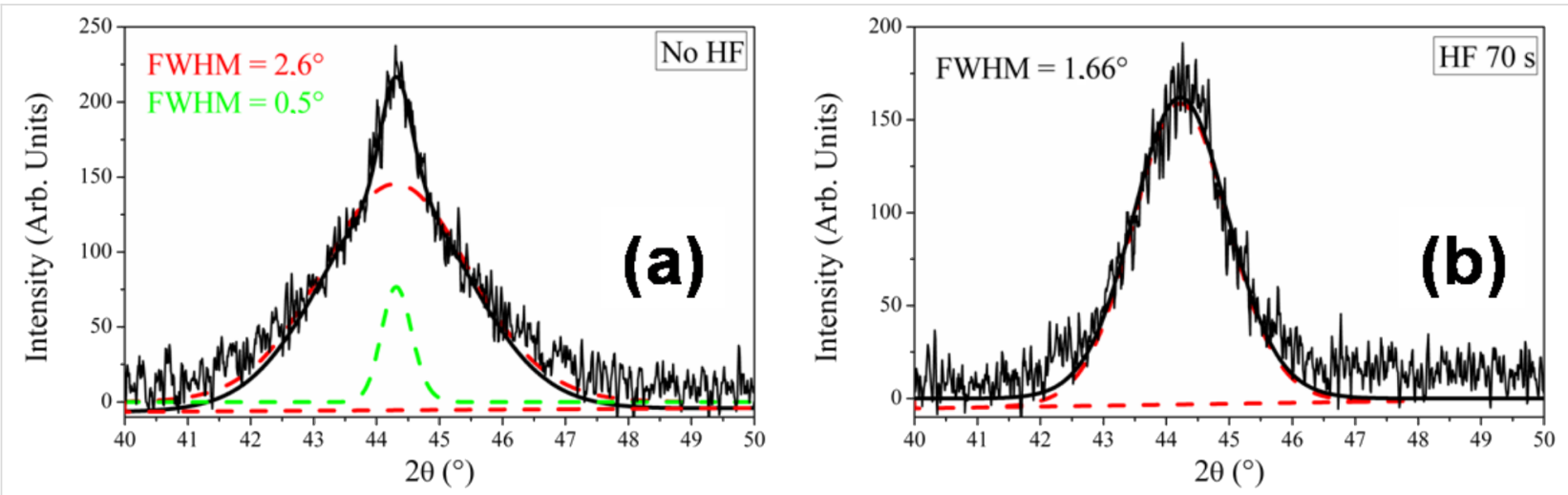

Figure 6: Au (200) peak as measured by XRD in Bragg-Brentano geometry of (a) as-deposited sample and (b) the same sample but after an HF treatment for $70 \mathrm{~s}$. 
diffraction profile is represented by the Gaussian shape with a FWHM of $0.5^{\circ}$. The same analysis was repeated after immersion of the sample in HF for $70 \mathrm{~s}$, and the diffractogram is shown in Figure 6b. The FWHM for the XRD profile decreases with increasing time in $\mathrm{HF}$ and is $2.26^{\circ}$ after $40 \mathrm{~s}$ and $1.66^{\circ}$ after $70 \mathrm{~s}$, indicating a thickening of the islands along the growth axis (3.8 $\mathrm{nm}$ and $5 \mathrm{~nm}$, respectively). The results are in agreement with the TEM images that predicted an "in-plan" shrinkage plus "in-height" increase for gold structures. We probed the modification in the crystalline orientation, as found by SAED, by comparing the "heteroepitaxial ratio", defined as:

$$
R_{\text {h.e. }}=\frac{\left(A_{200} / A_{111}\right)_{\text {as-dep }}}{\left(A_{200} / A_{111}\right)_{\text {post_HF }}}
$$

where $A$ is the area under the corresponding peak. $R_{\text {h.e. }}$ is a parameter related to the degree of texturing exhibited by the $\mathrm{Au}$ particles as a function of the HF treatment. The ratio amounts to 1.17 after $40 \mathrm{~s}$ and to 1.75 after $70 \mathrm{~s}$, indicating a reduction of the textured component with immersion time in the HF solution.

\section{Conclusion}

In this work we investigate the morphology of gold aggregates on silicon (100) substrates obtained by galvanic displacement using XRD, AFM and TEM (with a proper low-energy ion milling procedure). It was shown that $\mathrm{Au}$ atoms assemble in thin regions and are irregularly shaped and also form in 3D spherical clusters. The 3D spherical clusters form according to the layer-by-layer and island growth modes but it is possible to select between the two by varying the immersion time in DHF solution during the cleaning procedure. Specifically, after a quick immersion time of about $10 \mathrm{~s}$ and a deposition time of $3 \mathrm{~s}$, we obtained a discontinuous gold film of a few monolayers thick. When the HF pretreatment is extended up to $4 \mathrm{~min}$, for the same plating time, we observed mostly spherical clusters, while the thin regions were reduced to small squares of a few nanometers long, which were aligned with the [001] direction of the substrate. With a $10 \mathrm{~s}$ HF pretreatment and longer deposition times (about $20 \mathrm{~s}$ ), both structures coexist, corroborating the layer-by-layer plus island growth modes for gold on silicon. The SAED and the XRD measurements showed a pronounced heteroepitaxial component but also a polycrystalline phase for $\mathrm{Au}$ on $\mathrm{Si}(100)$ obtained by galvanic displacement. The layered gold regions could be altered by means of postdeposition HF treatments. TEM observations and XRD analysis showed that they thicken and rearrange their own crystalline structure.
$\mathrm{HF}$ is known to etch $\mathrm{SiO}_{2}$, changing the surface chemical composition and also the free energy of Si. As a result, the layered gold is freed and the outlying atoms move toward inner regions to reduce their surface free energy. The process is very fast and bears similarities with the HF self-propelled motion of liquid droplets on solid surfaces [39]. The results are comparable to those obtained after high temperature and/or time consuming annealing procedures.

\section{Experimental}

Pretreatment of silicon substrate and metal deposition. The starting substrate was a $\operatorname{Si}(100)$ n-type substrate with $\rho=3-5 \Omega \mathrm{cm}$. Prior to plating, each sample was cut into squares of $1.5 \times 1.5 \mathrm{~cm}$ and degreased in acetone at $60^{\circ} \mathrm{C}$ and then placed in an ultrasonic bath for $6 \mathrm{~min}$. This was followed by immersion in DHF ( $6 \% \mathrm{HF})$ for $10 \mathrm{~s}$ or $240 \mathrm{~s}$. The substrates were then thoroughly washed with deionized water and blow-dried in air. Gold deposition was carried out by manually soaking each sample in a solution containing $1 \mathrm{mM} \mathrm{KAuCl}_{4}$ (99.995\% trace metal, Sigma-Aldrich) and 10\% HF (diluted HF, GPR RECTAPUR 40\%, VWR) at room temperature, under ambient light conditions and without stirring. Then the samples were rinsed in water to remove all surfactants and products. They received an additional cleaning in acetone and were dried in air.

TEM sample preparation. For plan view, the samples were mechanically thinned from the backside to less than a micrometer. Then they were milled with a Gatan PIPS II device, according to a low-energy procedure. Gentle milling was performed at low temperature (less than $-100{ }^{\circ} \mathrm{C}$ with $\mathrm{LN}_{2}$ cooling) at a $6^{\circ}$ milling angle and with beam energy of $1 \mathrm{keV}$ and current of $30 \mu \mathrm{A}$ at the beginning and of $0.1 \mathrm{keV}$ and $25 \mu \mathrm{A}$ for final polishing.

\section{Supporting Information}

We provide images for further understanding of the influence of the TEM thinning procedures and we give evidence of the random rearrangement of gold atoms by electron diffraction on a selected area. We also show the Rutherford backscattering spectra of the samples before and after the HF postdeposition treatments to demonstrate that the amount of gold atoms does not change.

\section{Supporting Information File 1}

Additional experimental data.

[http://www.beilstein-journals.org/bjnano/content/ supplementary/2190-4286-8-19-S1.pdf] 


\section{Acknowledgements}

The authors are grateful to Dr. F. Ruffino for his precious AFM analysis.

\section{References}

1. Kolasinski, K. W. Curr. Opin. Solid State Mater. Sci. 2006, 10, 182-191. doi:10.1016/j.cossms.2007.03.002

2. Schimdt, V.; Senz, S.; Gösele, U. Nano Lett. 2010, 5, 931-935. doi:10.1021/nl050462g

3. Garozzo, C.; La Magna, A.; Mannino, G.; Scalese, S.; Sberna, P. M.; Simone, F.; Puglisi, R. A. J. Appl. Phys. 2013, 113, 214313. doi:10.1063/1.4809557

4. Han, H.; Huang, Z.; Lee, W. Nano Today 2014, 9, 271-304. doi:10.1016/j.nantod.2014.04.013

5. Schmid, G.; Simon, U. Chem. Commun. 2005, 697-710. doi:10.1039/B411696H

6. Noguez, C. J. Phys. Chem. C 2007, 111, 3806-3819. doi:10.1021/jp066539m

7. Ammari, H.; Deng, Y.; Millien, P. Arch. Ration. Mech. Anal. 2016, 220, 109-153. doi:10.1007/s00205-015-0928-0

8. Jeong, S.-H.; Choi, H.; Kim, J. Y.; Lee, T.-W. Part. Part. Syst. Charact. 2015, 32, 164-175. doi:10.1002/ppsc.201400117

9. Stratakis, E.; Kymakis, E. Mater. Today 2013, 16, 133-146. doi:10.1016/j.mattod.2013.04.006

10. Lu, R.; Xu, L.; Ge, Z.; Li, R.; Xu, J.; Yu, L.; Chen, K. Nanoscale Res. Lett. 2016, 11, 160. doi:10.1186/s11671-016-1374-0

11. Song, Y.-Y.; Gao, Z.-D.; Kelly, J. J.; Xia, X.-H. Electrochem. Solid-State Lett. 2005, 8, C148-C150. doi:10.1149/1.2033616

12. Quu, T.; Chu, P. K. Mater. Sci. Eng., R 2008, 61, 59-77. doi:10.1016/j.mser.2008.03.001

13. Yae, S.; Nasu, N.; Matsumoto, K.; Hagihara, T.; Fukumuro, N.; Matsuda, H. Electrochim. Acta 2007, 53, 35-41. doi:10.1016/j.electacta.2007.04.058

14. Soejima, T.; Katayama, Y.; Fuji, S. CrystEngComm 2016, 18, 6683-6688. doi:10.1039/C6CE01199C

15. Wang, T.; Hu, F.; Ikhile, E.; Liao, F.; Li, Y.; Shao, M. J. Mater. Chem. C 2015, 3, 559-563. doi:10.1039/C4TC02310B

16. Zhao, L.; Siu, A. C.-L.; Petrus, J. A.; He, Z.; Leung, K. T. J. Am. Chem. Soc. 2007, 129, 5730-5734. doi:10.1021/ja070441j

17. Ruffino, F.; Grimaldi, M. G. J. Appl. Phys. 2010, 107, 104321. doi:10.1063/1.3428467

18. Andersson, T. G. Gold Bull. 1982, 15, 7-18. doi:10.1007/BF03216565

19. Okuno, K.; Ito, T.; Iwami, M.; Hiraki, A. Solid State Commun. 1980, 34, 493-497. doi:10.1016/0038-1098(80)90659-6

20. Hiraki, A.; Iwami, M. Jpn. J. Appl. Phys. 1974, 13, 749. doi:10.7567/JJAPS.2S2.749

21. Sayed, S. Y.; Wang, F.; Malac, M.; Meldrum, A.; Egerton, R. F.; Buriak, J. M. ACS Nano 2009, 3, 2809-2817. doi:10.1021/nn900685a

22. Li, B.; Huang, L.; Zhou, M.; Fan, X.; Ma, M. J. Wuhan Univ. Technol., Mater. Sci. Ed. 2012, 29, 651-655. doi:10.1007/s11595-014-0973-9

23. Milazzo, R. G.; Mio, A. M.; D’Arrigo, G.; Spinella, C.; Grimaldi, M. G.; Rimini, E. IEEE Nanotechnol. Mater. Devices Conf. 2014, 37-40. doi:10.1109/NMDC.2014.6997416

24. Imama, H.; Elsayed, K.; Ahmed, M. A.; Ramdan, R. Opt. Photonics J. 2012, 2, 73-84. doi:10.4236/opj.2012.22011
25. Garozzo, C.; Filetti, A.; Bongiorno, C.; La Magna, A.; Simone, F.; Puglisi, R. A. Gold Bull. 2014, 47, 185-193. doi:10.1007/s13404-014-0142-0

26. Trucks, G. W.; Raghvachari, K.; Higashi, G. S.; Chabal, Y. J. Phys. Rev. Lett. 1990, 65, 504. doi:10.1103/PhysRevLett.65.504

27. Takahagi, T.; Nagai, I.; Ishitani, A.; Kuroda, H.; Nagasawa, Y. J. Appl. Phys. 1998, 64, 3516-3521. doi:10.1063/1.341489

28. Ubara, H.; Imura, T.; Hiraki, A. Solid State Commun. 1984, 50, 673-675. doi:10.1016/0038-1098(84)90156-X

29. Higashi, G. S.; Chabal, Y. J.; Trucks, G. W.; Raghavachari, K. Appl. Phys. Lett. 1990, 56, 656-658. doi:10.1063/1.102728

30. Kumar, V.; Bhat, K. N.; Sharma, N. N. J. Adhes. Sci. Technol. 2015, 29, 308-318. doi:10.1080/01694243.2014.986835

31. Tu, K. N.; Mayer, W. J.; Feldman, L. C. Electronic thin film science for electrical engineering and material scientist; Macmillan, 1992.

32. Monk, D. J.; Soane, D. S.; Howe, R. T. Thin Solid Films 1993, 232, 1-12. doi:10.1016/0040-6090(93)90752-B

33. Kubiak, K. J.; Wilson, M. C. T.; Mathia, T. G.; Carval, P. Wear 2011, 271, 523-528. doi:10.1016/j.wear.2010.03.029

34. Stoldt, C. R.; Jenks, C. J.; Thiel, P. A.; Cadilhe, A. M.; Evans, J. W. J. Chem. Phys. 1999, 111, 5157-5166. doi:10.1063/1.479770

35. Gerber, T.; Knudesn, J.; Feilbelman, P. J.; Grånäs, E.; Stratmann, P.; Schulte, K.; Andersen, J. N.; Michely, T. ACS Nano 2013, 7, 2020-2031. doi:10.1021/nn400082w

36. Polte, J. CrystEngComm 2015, 17, 6809-6830. doi:10.1039/C5CE01014D

37. Milazzo, R. G.; Mio, A. M.; D’Arrigo, G.; Grimaldi, M. G.; Spinella, C.; Rimini, E. J. Chem. Phys. 2015, 143, 024306. doi:10.1063/1.4926530 38. Scherrer, P. Nachr. Ges. Wiss. Göttingen 1918, 1918, 98-100.

39. Yao, X.; Bai, H.; Ju, J.; Zhou, D.; Li, J.; Zhang, H.; Yang, B.; Jiang, L. Soft Matter 2012, 8, 5988-5991. doi:10.1039/c2sm25153a

\section{License and Terms}

This is an Open Access article under the terms of the Creative Commons Attribution License (http://creativecommons.org/licenses/by/4.0), which permits unrestricted use, distribution, and reproduction in any medium, provided the original work is properly cited.

The license is subject to the Beilstein Journal of Nanotechnology terms and conditions: (http://www.beilstein-journals.org/bjnano)

The definitive version of this article is the electronic one which can be found at: doi:10.3762/bjnano.8.19 